\title{
Corrigendum to "Impaired Fertility Associated with Subclinical Hypothyroidism and Thyroid Autoimmunity: The Danish General Suburban Population Study"
}

\author{
Anne-Dorthe Feldthusen, ${ }^{1,2}$ Palle L. Pedersen, ${ }^{2,3}$ Jacob Larsen, ${ }^{2,4}$ Tina Toft Kristensen, ${ }^{2,5}$ \\ Christina Ellervik, ${ }^{6,7}$ and Jan Kvetny ${ }^{2,8,9}$ \\ ${ }^{1}$ Department of Obstetrics \& Gynaecology, Naestved Hospital, Ringstedgade 61, 4700 Naestved, Denmark \\ ${ }^{2}$ The Mitochondrial Research Unit, Naestved Hospital, Ringstedgade 61, 4700 Naestved, Denmark \\ ${ }^{3}$ Department of Clinical Biochemistry, Naestved Hospital, Ringstedgade 61, 4700 Naestved, Denmark \\ ${ }^{4}$ Department of Clinical Pathology, Naestved Hospital, Ringstedgade 61, 4700 Naestved, Denmark \\ ${ }^{5}$ Department of Otorhinolaryngology-Head and Neck Surgery, Koege Hospital, Lykkebaekvej 1, 4600 Koege, Denmark \\ ${ }^{6}$ Department of Research, Nykoebing F. Hospital, 4800 Nykobing Falster, Denmark \\ ${ }^{7}$ Department of Clinical Medicine, Faculty of Health and Medical Sciences, University of Copenhagen, Denmark \\ ${ }^{8}$ Department of Internal Medicine, Naestved Hospital, Ringstedgade 61, 4700 Naestved, Denmark \\ ${ }^{9}$ Institute of Regional Health Services, University of Southern Denmark, Denmark \\ Correspondence should be addressed to Anne-Dorthe Feldthusen; adf@dadlnet.dk
}

Received 28 August 2017; Accepted 27 September 2017; Published 5 November 2017

Copyright (c) 2017 Anne-Dorthe Feldthusen et al. This is an open access article distributed under the Creative Commons Attribution License, which permits unrestricted use, distribution, and reproduction in any medium, provided the original work is properly cited.

In the article titled "Impaired Fertility Associated with Subclinical Hypothyroidism and Thyroid Autoimmunity: The Danish General Suburban Population Study" [1], there were errors in Materials and Methods and Results described as follows.

In Section "2.1. Study Population," the sentence "All individuals older than 30 years were invited" should be changed to "All individuals older than or equal to 30 years were invited." In addition, the sentence "In this study we included participants of European origin (99\% Danish) ( $N=$ 11387) and excluded participants with missing values of TSH, fT4, and tT3 $(N=50)$ and missing values of the number of pregnancies, the number of children born, and the number of spontaneous abortions $(N=31)$ " should be changed to "In this study we included participants of European origin (99\% Danish $)(N=11387)$ and excluded participants with missing values of TSH, fT4, and tT3 $(N=50)$ and missing values of the number of pregnancies, the number of children born, and the number of spontaneous abortions $(N=83)$."
In "Results," the sentence "Table 1 shows characteristics of women. In total, 758 (6.7\%) had mild (subclinical) hypothyroidism, 9.4\% prevalent hypothyroidism, and $4.2 \%$ prevalent hyperthyroidism" should be changed to "Table 1 shows characteristics of women. In total, 758 (6.7\%) had mild (subclinical) hypothyroidism, $8.2 \%$ prevalent hypothyroidism, 3.5\% prevalent hyperthyroidism, and $4.2 \%$ prevalent hyperthyroidism." Therefore, Table 1 should be corrected as follows. 


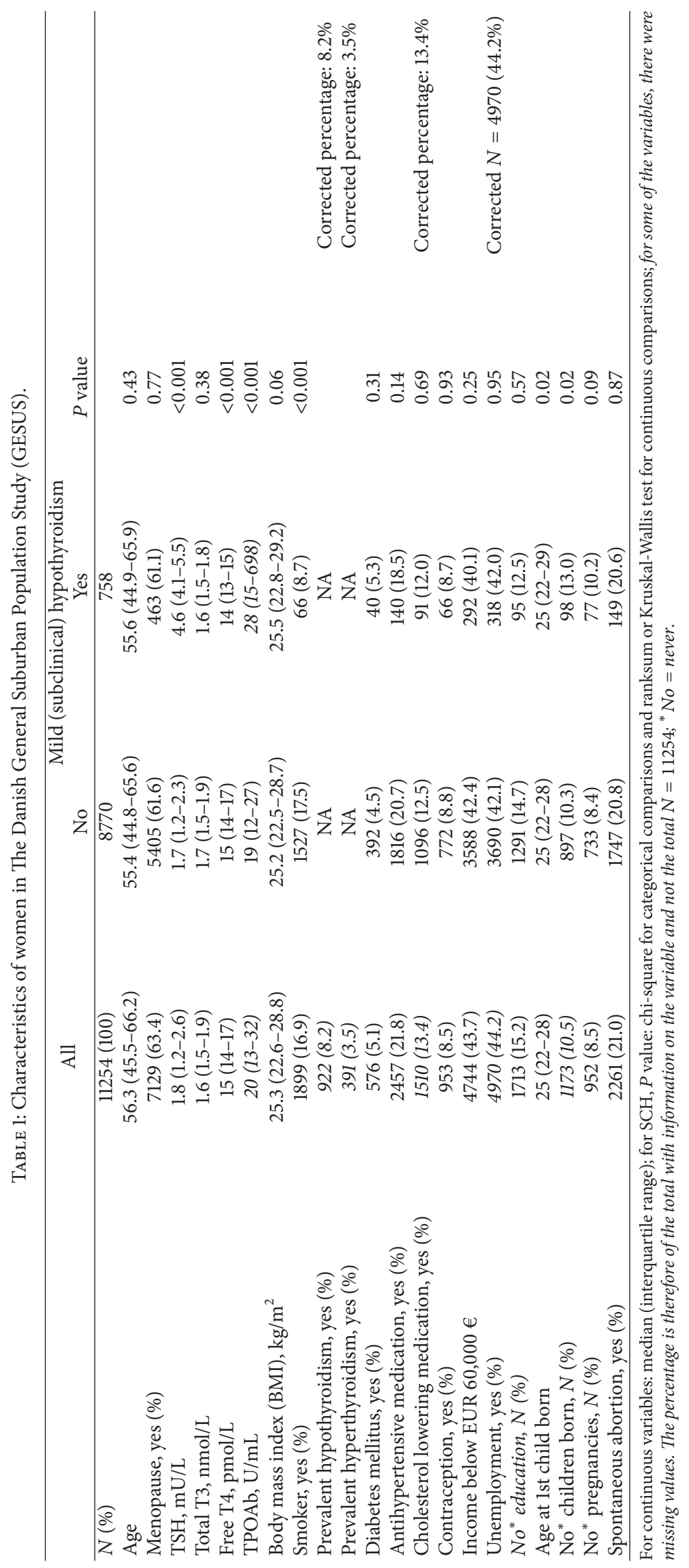




\section{References}

[1] A.-D. Feldthusen, P. L. Pedersen, J. Larsen, T. Toft Kristensen, C. Ellervik, and J. Kvetny, "Impaired fertility associated with subclinical hypothyroidism and thyroid autoimmunity: the danish general suburban population study," Journal of Pregnancy, vol. 2015, Article ID 132718, 6 pages, 2015. 


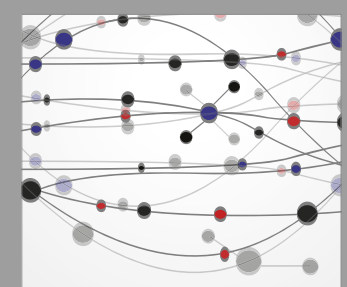

The Scientific World Journal
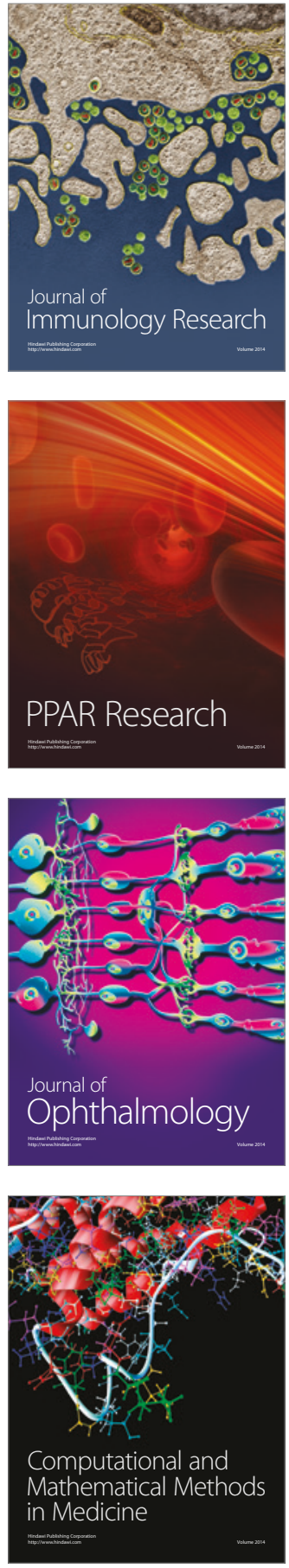

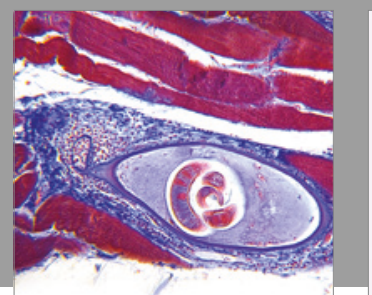

Gastroenterology Research and Practice
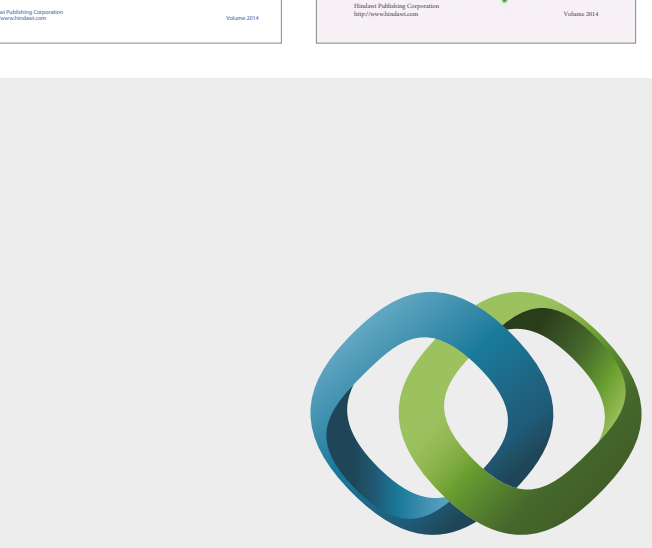

\section{Hindawi}

Submit your manuscripts at

https://www.hindawi.com
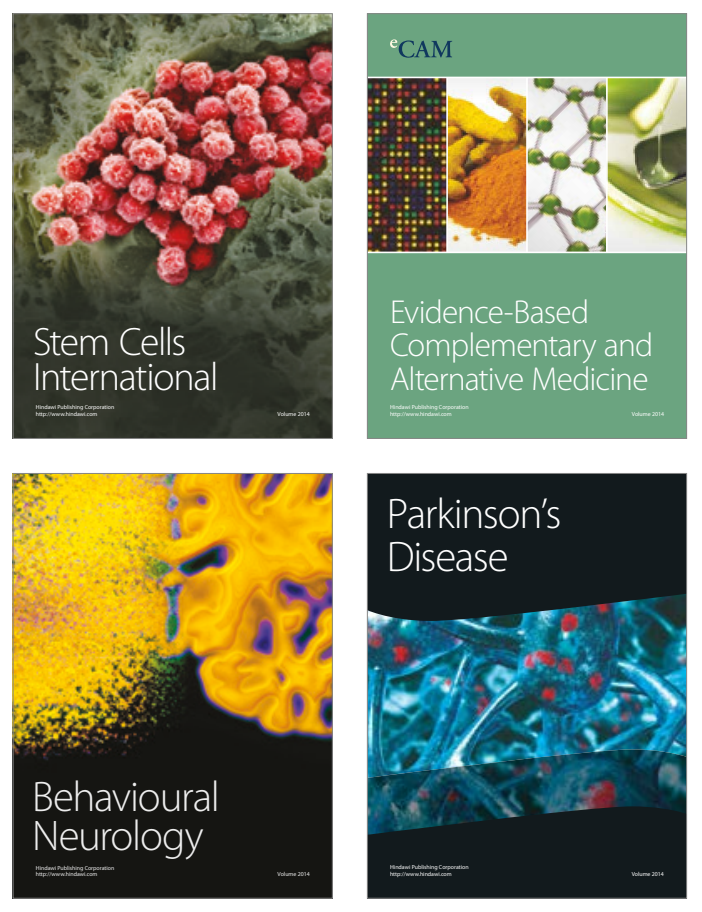
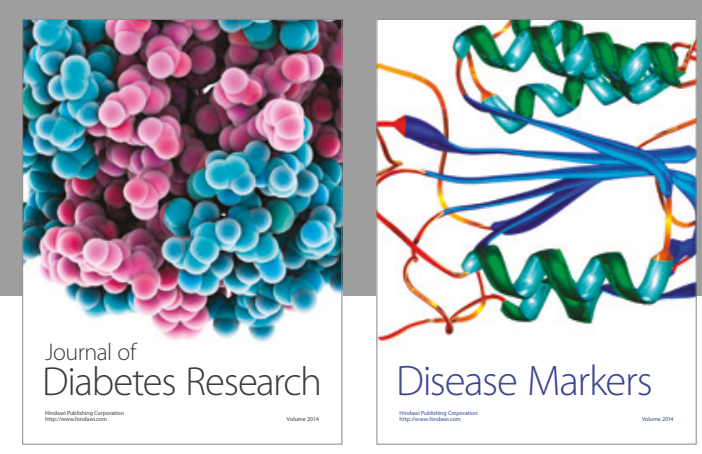

Disease Markers
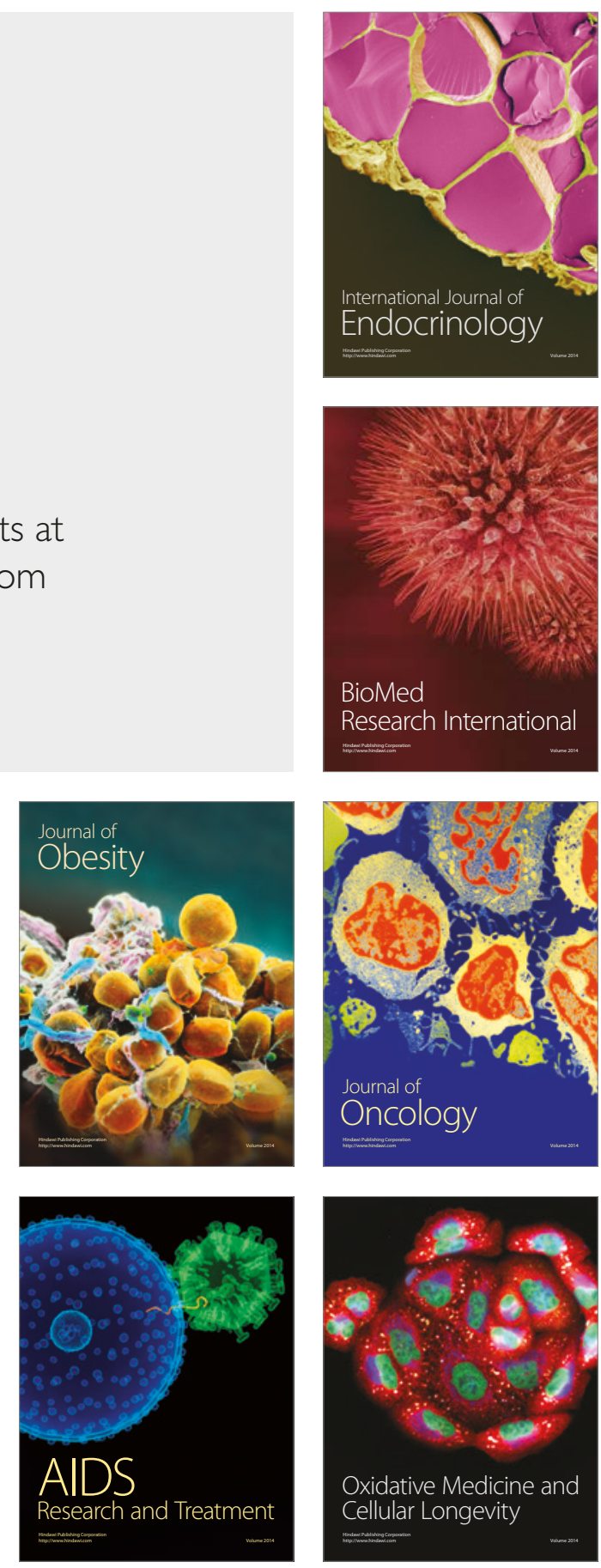